\title{
GEOLOGIA E GEOQUIMICA DO LEUCOGRANITO ARQUEANO POTÁSSICO MATA SURRÃO, TERRENO GRANITO-GREENSTONE DE RIO MARIA, PARÁ
}

\author{
K.D.Duarte, R.Dall'Agnol
}

O Terreno Granito-Greenstone de Rio Maria (TGGRM) formou-se e estabilizou-se tectonicamente durante o Arqueano (Macambira, 1992; Pimentel \& Machado, 1994; Macambira \& Lafon, 1994). Nele foram recentemente distinguidos três grandes grupos de associações granitóides de idade arqueana (Dall'Agnol et al., 1996): (1) Granitóides da série trondhjemitica, representados pelo Tonalito Arco Verde (Althoff et al., 1991, no prelo), Trondhjemito Mogno (Huhn et al., 1988; Souza, 1994) e tonalitos gnáissicos de Xinguara (Leite, 1995). (2) Granodiorito Rio Maria e rochas afins, pertencentes à série cálcico-alcalina de médio potássio. (3) Leucogranitóides com composições dominantemente monzograníticas, de afinidades cálcico-alcalinas, enriquecidos em potássio e altamente fracionados.

O objetivo do presente trabalho é apresentar e discutir as principais características do Granito Mata Surrão, representativo do terceiro grupo de granitóides. 0 mesmo aflora a sudoeste da cidade de Rio Maria e foi adotado como representativo dessa tipologia de granito na região (Suíte Mata Surrão; Araújo, 1994). Ele foi estudado e descrito originalmente por Duarte et al. (1991) e Duarte (1992). Ele forma um stock de rochas graniticas relativamente homogêneas e pouco deformadas, o qual secciona o Tonalito Arco Verde $(2,96 \mathrm{Ga}$; Macambira, 1992). Xenólitos do último são freqüentes no Granito Mata Surrão, que engloba ainda enclaves dioríticos a quartzo-dioríticos ricos em anfibólio. Uma foliação desenvolve-se apenas nas bordas do corpo e não é penetrativa. As amostras de mão não revelam em geral evidências nitidas de deformação, a qual é mais evidente ao microscópio, sobretudo no quartzo. 0 corpo apresenta em mais de um local estruturas bandadas que foram interpretadas como igneous layering.

Sua datação pelo método $\mathrm{Rb} / \mathrm{Sr}$ acusou uma idade de $2541 \pm 74 \mathrm{Ma}$ com razão inicial de 0,71040 \pm 343 (Duarte et al., 1991), enquanto que o método $\mathrm{Pb} / \mathrm{Pb}$ em rocha total revelou uma idade de $2875 \pm 20 \mathrm{Ma}$ (Macambira \& Lafon, 1994). Essa última idade é coincidente com aquela obtida para o Granodiorito Rio Maria (Macambira, 1992; Pimentel \& Machado, 1994), sendo interpretada como a idade de cristalização do Granito Mata Surrão. $O$ significado da idade $\mathrm{Rb} / \mathrm{Sr}$ ainda não está totalmente esclarecido, mas ela é coincidente com aquelas obtidas nos demais granitóides arqueanos do TGGRM. As relações de campo e os dados geocronológicos levam a posicionar o Granito Mata Surrão como representativo dos últimos eventos graníticos do TGGRM, datados de $2,87 \mathrm{Ga}$.

O Granito Mata Surrão é formado por biotita leucomonzogranitos que apresentam quantidades apreciáveis de epidoto - com feições texturais que fazem suspeitar de sua origem magmática - e muscovita, além de allanita, zircão, apatita e clorita como fases acessórias, sendo a última secundária. Possui variações locais para granodioritos.

Grupo de Pesquisa Petrologia de Granitos (GPPG), CG, Universidade Federal do Pará. 
Os dados geoquímicos mostram composições graníticas ricas em $\mathrm{SiO}_{2}$ (74,73\%; média de 12 amostras), $\mathrm{Al}_{2} \mathrm{O}_{3}(14,46 \%)$ e $\mathrm{K}_{2} \mathrm{O}(4,68 \%)$ e pobres em $\mathrm{FeO}+\mathrm{Fe}_{2} \mathrm{O}_{3}(0,50$ $+0,55 \%$, respectivamente), $\mathrm{MgO}(0,29 \%)$ e $\mathrm{TiO}_{2}(0,16 \%)$. Os conteúdos de $\mathrm{CaO}(1,24 \%)$ e $\mathrm{Na}_{2} \mathrm{O}(3,59 \%)$ são moderados. As razões $\mathrm{K}_{2} \mathrm{O} / \mathrm{Na}_{2} \mathrm{O}$ são sempre maiores que a unidade e o mesmo ocorre com a maioria das razões $\mathrm{Rb} / \mathrm{Sr}$. Os teores de $\mathrm{Y}$ e $\mathrm{Nb}$ são baixos e os de $\mathrm{Zr}$ moderados.

Os granitos são peraluminosos (corindon normativo variando de 0,10 a $1,74 \%$, atingindo numa amostra isolada $3,68 \%$ ). Apresentam afinidades cálcico-alcalinas, seguindo o trend correspondente em diagrama $\mathrm{K}_{2} \mathrm{O} \times \mathrm{Na}_{2} \mathrm{O} \times \mathrm{CaO}$. No diagrama normativo An$\mathrm{Ab}-\mathrm{Or}$ plotam indistintamente no campo dos granitos. No diagrama R1-R2 dispõem-se segundo um trend subalcalino. Os elementos traço sugerem analogias geoquímicas com granitos colisionais do Fanerozóico. Resumindo, as características geoquimicas indicam que o Granito Mata Surrão é um granito dominantemente potássico, altamente fracionado com afinidade cálcico-alcalina. Ele diverge em vários aspectos (conteúdos de $\mathrm{Al}_{2} \mathrm{O}_{3}, \mathrm{Rb}, \mathrm{Y}, \mathrm{Nb}$ e $\mathrm{Zr}$, entre outros) dos granitos anorogênicos da região de Rio Maria e se assemelha muito com o Granito Xinguara (Leite, 1995), outro exemplo de leucogranito arqueano do TGGRM

Os leucogranitos do TGGRM mostram muitas semelhanças geoquímicas com os granitos potássicos tardios de outros terrenos arqueanos do globo (Leite, 1995) e se distinguem claramente das demais séries de granitóides arqueanos, com as quais ocorrem associados. A sua petrogênese necessita ser melhor investigada em trabalhos futuros, mas admite-se como hipótese preliminar a sua derivação a partir da fusão em condições crustais, de granitóides arqueanos mais antigos.

\section{Referências Bibliográficas}

ALTHOFF, F.J. et al. (no prelo) Boletim Museu Paraense Emilio Goeldi.

ALTHOFF, F.J.; DALL'AGNOL, R.; SOUZA, Z.S. (1991) Região de Marajoara-SE do Pará: prolongamento dos terrenos arqueanos de Rio Maria ou retrabalhamento? In: SIMPÓSIO DE GEOLOGIA DA AMAZÔNIA, 3., Belém, 1991. Anais. Belém, SBG-Núcleo Norte. v.3, p.130-141.

ARAÚJO, O.J.B.; MACAMBIRA, E.M.B.; VALE, A.G.; OLIVEIRA, J.R.; SILVA NETO, C.S.; COSTA, E.J.S.; SANTOS, A.; PENA FILHO, J.I.C.; NEVES, A.P.; JOÃO, X.S.J.; COSTA, J.V.S. (1994) Primeira integração das investigações geológicas do programa grande Carajás na região SE do estado do Pará. In: SIMPÓSIO DE GEOLOGIA DA AMAZÔNIA, 4., Belém, 1994. Boletim de Resumos Expandidos. Belém, SBG- NO, p.299-301.

DALL'AGNOL, R. et al. (1996) In: SYMP. ARCH. TERR. p.29-30.

DUARTE, K.D.; PEREIRA, E.D.; DALL'AGNOL, R.; LAFON, J.M. (1991) Geologia e geocronologia do granito Mata Surrão-Sudoeste de Rio Maria (PA). In: SIMPÓSIO DE GEOLOGIA DA AMAZÔNIA, 3., Belém, 1991. Anais. Belém, SBG-NO, p.7-20.

DUARTE, K.D. (1992) Tese Mestrado, CPGG/UFPA.

HUHN, S.R.B.; SANTOS, A.B.S.; AMARAL, A.F.; LEDSHAM, E.J.; GOUVEA, J.L.; MARTINS, L.P.B.; MONTALVÃO, R.G.M.; COSTA, V.G. (1988) 0 terreno granito greenstone da região de Rio Maria - Sul do Pará. In: CONGRESSO BRASILEIRO DE GEOLOGIA, 35., Belém, 1988. Anais. Belém, SBG. p.1438-1452.

LEITE, A.A.S. (1995) Geologia e geoquímica do maciço granítico arqueano Xinguara e de suas encaixantes, sudeste do estado do Pará. Belém, 209p. (Tese - Mestrado) - Centro de Geociências, Universidade Federal do Pará. 
MACAMBIRA, M.J.B. (1992) Chronologie U/Pb, Sr, K/Ar et croissance de la croûte continentale dans L'Amazonie du sud-est; exemple de la région de Rio Maria, Province de Carajás, Brésil. Montpellier, 212p. (Tese - Doutorado) - Université Montpellier II.

MACAMBIRA, M.J.B.; LAFON, J.M. (1994) In: SIMPÓSIO DE GEOLOGIA DA AMAZÔNIA, 4., Belém, 1994. Boletim de Resumos Expandidos. Belém, SBG-NO, p.339-342.

PIMENTEL, M.M.; MACHADO, N. (1994) Geocronologia U-PB dos terrenos granitogreenstone de Rio Maria, Pará. In: CONGRESSO BRASILEIRO DE GEOLOGIA, 38., Camboriú, 1994. Boletim de Resumos Expandidos. Camboriú, SBG. v.2, p.390-391.

SOUZA, Z.S. (1994) Tese - Doutorado, CPGG/UFPA. 